\title{
Effect of UV-B radiation on the fatty acid composition of the marine phytoplankter Tetraselmis sp.: relationship to cellular pigments
}

\author{
Joaquim I. Goes ${ }^{1,3}$, Nobuhiko Handa ${ }^{1}$, Satoru Taguchi ${ }^{2}$, Takeo Hama ${ }^{1}$ \\ ${ }^{1}$ Institute for Hydrospheric-Atmospheric Sciences, Nagoya University, Chikusa-ku 464, Japan \\ ${ }^{2}$ Hokkaido National Fisheries Research Institute, Kushiro 085, Japan \\ ${ }^{3}$ National Institute of Oceanography, Dona Paula, Goa 403004, India
}

\begin{abstract}
The effect of UV-B (280 to $320 \mathrm{~nm}$ ) radiation on the fatty acid and pigment composition of Tetraselmis sp. was examined as part of a larger effort to understand the possible consequences of an enhancement in natural levels of UV-B radiation on photosynthetic processes in marine phytoplankton. At levels that still permitted the assimilation of carbon within the cell, UV-B radiation induced a rapid increase in intracellular carotenoids and a marked decline in chlorophyll a. Absolute concentrations of fatty acids within the cells were lower in presence of UV-B, attributable largely to suppression of polyunsaturated fatty acid (PUFA) synthesis. The supprossion of PUFAs by UV-B radiation and the inability of the cells to produce these compounds in the dark suggests that over a diel cycle, if natural phytoplankton are exposed to UV-B radiation during the day, the cells may be incapable of restoring the cellular balance of fatty acids during the night. Amongst the PUFAs, the production of 16:4 was highly susceptible to UV-B radiation. In contrast, the production of the saturated fatty acid $16: 0$ continued unabated in the presence of UV-B radiation. The carbon weight ratio of 16:0 to 16:4 related well with the dose of UV-B radiation and appears to be a promising indicator of UV-B induced stress in green algae. A hypothesis explaining the selective suppression of cellular PUFA synthesis, in particular that of $16: 4$ by UV-B, is presented and discussed in relation to concurrent changes in intracellular pigments. The implications of enhanced UV-B radiation on the marine food chain and on biogeochernical cycling in the sea are discussed in the light of these findings.
\end{abstract}

KEY WORDS: UV-B radiation - Marine phytoplankton - Fatty acids · Pigments

\section{INTRODUCTION}

The enhancement of UV-B ( 280 to $320 \mathrm{~nm}$ ) radiation in the environment resulting from a reduction in the thickness of the ozone layer (Caldwell 1981, UNEP 1991) demands that we begin to question its consequences for all forms of life in the sea (Calkins \& Thordardottir 1980, Worrest 1982, Smith \& Baker 1989, Tevini 1993). Phytoplankton - the basis of the food chain and the carbon cycle in the sea - are particularly vulnerable to such changes in natural UV-B radiation since they depend on solar radiation for photosynthesis (Worrest \& Hader 1989). In a recent study, UV-B radiation values in excess of 75 and $15 \mu \mathrm{W} \mathrm{cm}{ }^{-2}$ were reported from a tropical and a temperate oceanic environment respectively (Herndl et al. 1993). In the Antarctic Ocean, UV-B values exceeding $90 \mu \mathrm{W} \mathrm{cm} \mathrm{cm}^{-2}$ were observed in association with the springtime decrease of stratospheric ozone (Karentz \& Lutze, 1990, Smith et al. 1992, Holm-Hansen et al. 1993). These values are well above the threshold levels at which suppression of phytoplankton photosynthesis by UV-B radiation has been observed (Cullen et al. 1992, Helbling et al. 1992), which suggests that even at the currently prevailing levels, UV-B radiation may affect the magnitude of phytoplankton production in the sea.

$U V-B$ radiation may suppress primary production either directly by depressing production of ATP (Vosjan et al. 1990), a compound required for the reduction and assimilation of carbon dioxide during photo- 
synthesis, or directly through its deleterious effects on the carbon-dioxide-reducing enzyme (Iwanzik et al. 1983, Dohler 1989a). UV-B radiation also has a negative influence on several other cellular enzymes and biochemical processes within phytoplankton (Newton et al. 1979, Dohler 1984, 1985, 1988, 1989a, b, 1990, 1992, Hader et al. 1986, Dohler et al. 1987, 1991), leading us to question whether an enhancement in natural levels of UV-B radiation could have a significant impact on the formation of biochemical compounds within phytoplankton celis. This question assumes considerable significance, as the biochemical composition of phytoplankton determines its nutritive value for higher trophic organisms (Watanabe et al. 1983) and is critical during growth and development of herbivores (Arnott et al. 1986, Huntley et al. 1987, Claustre et al. 1989). Despite this, there have been only a few studies which have examined the effect of UV-B radiation on the biochemical status of phytoplankton cells (Dohler 1984, 1989b, 1992 and references cited therein); this effect therefore remains largely unknown.

In a set of experiments designed to address this question, we examined the effects of UV-B radiation on a suite of processes related to photosynthesis and cell metabolism in a marine prasinophyte, Tetraselmis sp. At exposure levels that suppressed but still permitted the incorporation of carbon within the cells, UV-B radiation induced rapid and significant changes in the biochemical composition of the cells through its influence on the carbon assimilation patterns of photosynthesis. This report describes changes in the fatty acid and pigment composition of Tetraselmis sp. resulting from exposure to UV-B radiation. Although fatty acids constitute a small proportion of the total organic matter synthesized by marine phytoplankton (Hama \& Handa 1987. Hama 1991), they are critical for the growth of higher trophic organisms (Sargent \& Whittle 1981, Watanabe et al. 1983, Claustre et al. 1989, Siron et al. 1989). In the light of our findings, therefore, we have made an attempt to discuss the implications of UV-B radiation on the marine food chain and on material cycling in the sea.

\section{MATERIALS AND METHODS}

Experimental culture and set-up. All experiments were conducted with the unicellular marine prasinophyte Tetraselmis sp. obtained from the culture collection at the Hokkaido National Fisheries Research Institute, Hokkaido, Japan. Cells were grown in autoclaved f/2 medium (Guillard \& Ryther 1962) and maintained as semi-continuous cultures at $13^{\circ} \mathrm{C}$ under a $12 \mathrm{~h}$ light: $12 \mathrm{~h}$ dark cycle. Despite careful cleaning, we were unable to obtain completely bacteria-free culture sus- pensions. Photosynthetically active radiation (PAR, 400 to $700 \mathrm{~nm}$ ) was from Toshiba white light fluorescent lamps which provided a quantum scalar irradiance of $1.20 \mathrm{~mW} \mathrm{~cm}^{-2}$ as measured with a Biospherical $4 \pi$ sensor. UV-B radiation during the experiments came from 2 fluorescent lamps (Phillips ${ }^{\oplus}$, USA), which together provided an irradiance of $19 \mu \mathrm{W} \mathrm{cm}^{-2}$ as measured by a UVX radiometer (Model UVX-31). This intensity of UV-B radiation is equivalent to about $50 \%$ of the maximum value recorded by us during June off the east coast of Hokkaido, in the North Pacific Ocean (ca $32^{\circ} \mathrm{N}, 145^{\circ} \mathrm{E}$ ). The UV-B lamps were covered with cellulose acetate sheets to screen off shorter wavelengths ( $<280 \mathrm{~nm}$ ) not encountered in nature. The sheets were periodically examined for signs of discoloration and replaced as required.

Experiments were performed on mid-exponentialphase cultures, harvested $4 \mathrm{~h}$ into the light cycle. In order to avoid self-shading within the incubation bottles, the culture suspension was, if necessary, diluted with autoclaved culture medium before commencement of the experiments. At this stage duplicate aliquots of the culture suspension were filtered onto pre-combusted $\left(450^{\circ} \mathrm{C}\right)$ Whatman $\mathrm{GF} / \mathrm{F}$ filters for obtaining pre-incubation values of natural ${ }^{13} \mathrm{C}$, fatty acid and pigment composition of the cells.

In the first set of experiments, hereafter referred to as the long-term incubation experiment, the culture suspension was spiked with ${ }^{13} \mathrm{C}$-labeled bicarbonate (Hama et al. 1983) at a concentration of $18.5 \%$ of the total dissolved inorganic carbon in the medium and then transferred to a quadruplicate set of UV-B radiation transparent quartz bottles. Of the 4 bottles, 2 served as the controls and were covered with an acrylic sheet transparent to white light but opaque to UV-B light. When the experiments were begun, all 4 bottles were placed on a continuously agitating platform between a parallel array of horizontally placed UV-B lamps on one side and cool white fluorescent lamps on the other. To screen off any traces of UV-B radiation from the white fluorescent lamps, an acrylic sheet opaque to UV-B light was placed between these lamps and the bottles. The lamps were switched on at least $2 \mathrm{~h}$ before commencement of the incubation, which lasted for $12 \mathrm{~h}$. Measurements in the post-incubation samples included estimation of concentrations of pigments and fatty acids and incorporation of newly assimilated carbon into component fatty acids, in duplicate aliquots of the samples from each bottle filtered on precombusted GF/F filters.

In a second set of time-course experiments, hereafter referred to as the short-term incubation experiment, we attempted to examine the kinetics of changes in the cellular concentrations of fatty acids and pigments of Tetraselmis sp. under different UV-B radiation levels. 
Four different intensities of UV-B radiation were obtained by covering the UV-B exposed side of the quartz bottles with perforated neutral-density screens. A fifth bottle which was covered with an acrylic sheet opaque to UV-B served as a control. A sixth bottle completely covered with black tape and aluminum foil represented the dark incubated sample. Prior to commencement and at regular intervals during the experiment, duplicate aliquots of the incubated samples were filtered for analysis of absolute concentrations of cellular pigments and fatty acids. Incubations in the dark and in the presence of UV-B radiation were continued only for $300 \mathrm{~min}$, after which all the bottles were returned to control conditions. The incubations under control conditions were continued for another $120 \mathrm{~min}$.

Pigments analysis. Intracellular content of chlorophyll a (chl a), chl $b$ and carotenoids were estimated spectrophotometrically according to the method of Jeffrey \& Humphrey (1976) in 90\% acetone extracts of the samples filtered on Whatman ${ }^{(1)} \mathrm{GF} / \mathrm{F}$ filters. Standard deviations estimated from replicate measurements were in the range of 2 to $5 \%$ of the mean concentrations of each pigment.

Fatty acid analysis. Lipids were extracted from particulate matter onto pre-combusted $\left(450^{\circ} \mathrm{C}\right)$ Whatman ${ }^{(}$ GF/F filters according to the method described in Hama \& Handa (1987). Heneicosanoic acid (21:0) was added as an internal standard to the filters suspended in the chloroform/methanol (2:1 v/v) mixture. The lipid fraction in the chloroform phase obtained after removal of methanol and traces of moisture was saponified with $0.5 \mathrm{~N} \mathrm{KOH}$-methanol and then methylated using $\mathrm{BF}_{3}$-methanol at $100^{\circ} \mathrm{C}$ for $3 \mathrm{~h}$. Fatty acid methyl esters (FAME) thus obtained were extracted in $n$-hexane, dried under a stream of nitrogen and redissolved in chloroform. At this stage, in a slight departure from the normal procedure of Hama \& Handa (1987), a 'clean-up step' (K. Hayakawa pers. comm.) was included to remove traces of contaminating organic compounds which interfered with the gas chromatographic (GC) analysis of FAME. In this cleanup procedure, the FAME mixture in chloroform was applied to a solvent-treated and heat-activated silicacoated, thin-layer chromatographic (TLC) plate and then transferred to a saturated chamber containing hexane:benzene $(1: 1)$ as the mobile phase. Based on predetermined $R_{F}$ values for FAME, the silica coating along the horizontal axis of the TLC plates was carefully scraped and transferred to wide-bore pasteur pipettes. FAME adsorbed onto silica were extracted twice with methylene chloride, dried under nitrogen gas and redissolved in chloroform for $\mathrm{GC}$ analysis of absolute concentrations of fatty acids and for gas chromatographic-mass spectrometric (GC-MS) measure- ments of newly assimilated carbon into component fatty acids.

$G C$ analysis of FAME: Fatty acid methyl esters were analyzed using a Shimadzu GC 14 A equipped with a flame ionization detector and a fused silica capillary column (HR-SS-10, $25 \mathrm{~m} \times 0.25 \mathrm{~mm}$ i.d., Shinwah Kakoh $^{(}$, Japan). Nitrogen was used as the carrier gas. The injection and detection port temperatures were set at $220^{\circ} \mathrm{C}$ and the oven temperature was programmed from 120 to $230^{\circ} \mathrm{C}$ at $3^{\circ} \mathrm{C} \mathrm{min}^{-1}$ and then held at $230^{\circ} \mathrm{C}$ isothermally for $15 \mathrm{~min}$.

GC-MS analysis of FAME: The ${ }^{13} \mathrm{C}$ atom $\%$ of each fatty acid was estimated using a GC-MS (JEOL ${ }^{(}, \mathrm{DX}$ 302) equipped with a data system (JEOL ${ }^{\circledR}, J_{M A-D A}$ 2000E). A fused silica capillary column (HR-SS-10) was used for separation of the fatty acid derivatives which were introduced in succession into the mass spectrometer and subjected to chemical ionization (CI). Isobutane was used as the reagent gas and the chemical ionization spectra were obtained under the following conditions: ionization current, $300 \mu \mathrm{A}$; ionization potential, $210 \mathrm{eV}$ and ion source temperature, $250^{\circ} \mathrm{C}$. Repeat scanning was carried at a speed of $0.2 \mathrm{~s}$ and $\mathrm{a}$ scan interval of $1 \mathrm{~s}$ over the mass range from $\mathrm{m} / \mathrm{z}$ (mass to charge ratio) 200 to $500,{ }^{13} \mathrm{C}$ atom $\%$ of each fatty acid was calculated from the relative ratios of isotopic ion peaks to the quasimolecular ion peak according to Kouchi (1982). The accuracy of this method for estimation of ${ }^{13} \mathrm{C}$ atom \% has been discussed earlier in Hama (1991). Hama \& Handa (1992) and Hama et al. (1993). In the present study the coefficient of variation of replicate measurements was found to vary narrowly within $\pm 3 \%$ in comparison to the value of $\pm 1.2 \%$ reported by Hama \& Handa (1992). Production of each fatty acid was calculated utilizing GC and GC-MS data according to Hama et al. (1987). Possible discrimination of ${ }^{13} \mathrm{C}$ isotope during photosynthetic uptake was not considered in this study (Hama et al. 1993).

\section{RESULTS}

Cell counts were not monitored during these experiments and thus all concentration data refer to unit culture volume and not per cell.

\section{Pigment composition}

\section{Long-term incubation experiment}

There was a net increase in chl $a$, chl $b$ and carotenoids in the post-incubation samples of the longterm incubation experiments, indicating continuous production of these components even in the presence 
Table 1. Tetraselmis sp. Effect of UV-B radiation on pigment and fatty acid composition during the long-term incubation experiment. Pre-incubation and post-incubation (control) represent samples incubated under photosynthetically active radiation (PAR), whereas post-incubation (+UV-B) represents samples incubated under UV-B radiation (19 $\left.\mu \mathrm{W} \mathrm{cm}^{-2}\right)$ plus PAR

\begin{tabular}{|c|c|c|c|c|c|c|c|c|}
\hline \multirow[t]{2}{*}{ Treatment } & \multicolumn{4}{|c|}{ Pigments } & \multicolumn{4}{|c|}{ Fatty acids } \\
\hline & $\begin{array}{c}\text { ChI a } \\
\left(\mu \mathrm{ml}^{-1}\right)\end{array}$ & $\begin{array}{c}\text { Chl } b \\
\left(\mu g \mathrm{ml}^{-1}\right)\end{array}$ & $\begin{array}{c}\text { Carotenoids } \\
\left(\mu \mathrm{g} \mathrm{ml} \mathrm{m}^{-1}\right)\end{array}$ & $\begin{array}{c}\text { Carote- } \\
\text { noid:chl a }\end{array}$ & $\begin{array}{c}\text { Total } \\
\left(\mu \mathrm{g} \mathrm{C} \mathrm{ml}^{-1}\right)\end{array}$ & $\begin{array}{c}\text { Saturated } \\
(\%)\end{array}$ & $\begin{array}{l}\text { Monounsat- } \\
\text { urated }(\%)\end{array}$ & $\begin{array}{l}\text { Polyunsat- } \\
\text { urated }(\%)\end{array}$ \\
\hline Pre-incubation & 0.14 & 0.07 & 0.03 & 0.22 & 0.12 & 25.4 & 17.3 & 57.3 \\
\hline $\begin{array}{l}\text { Post-incubation } \\
+ \text { UV-B } \\
\text { Control }\end{array}$ & $\begin{array}{l}0.17 \\
0.23\end{array}$ & $\begin{array}{l}0.11 \\
0.14\end{array}$ & $\begin{array}{l}0.09 \\
0.05\end{array}$ & $\begin{array}{l}0.56 \\
0.22\end{array}$ & $\begin{array}{l}0.13 \\
0.20\end{array}$ & $\begin{array}{l}39.7 \\
27.8\end{array}$ & $\begin{array}{l}33.4 \\
21.4\end{array}$ & $\begin{array}{l}26.8 \\
51.9\end{array}$ \\
\hline
\end{tabular}
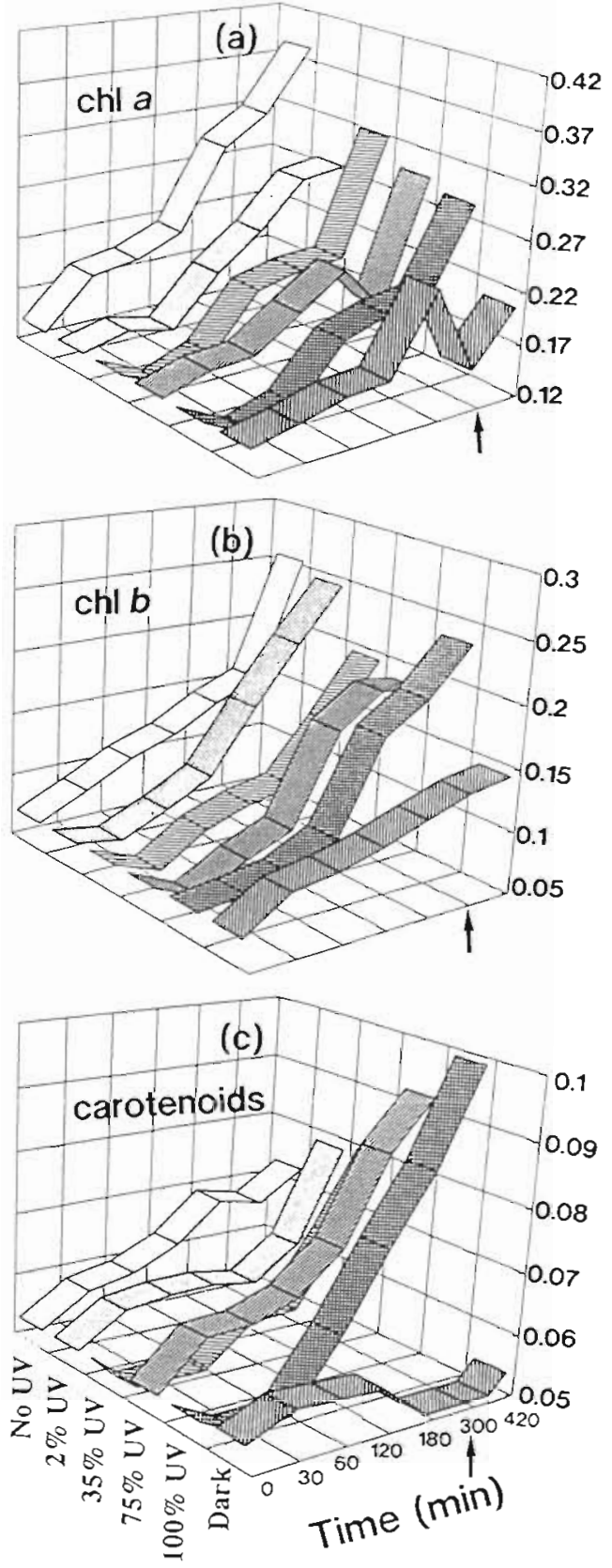

of UV-B radiation (Table 1). Chl $a$ and chl $b$ per ml concentrations were, however, lower by approximately 33 and $19 \%$ respectively in the presence of UV-B radiation in comparison to the sample under control conditions. On the other hand, carotenoid pigments were conspicuously higher by about $33 \%$ per $\mathrm{ml}$ in cells subject to UV-B radiation.

\section{Short-term incubation experiment}

The changes in pigment concentrations per unit culture volume of Tetraselmis sp. cells during the shortterm incubation experiment are shown in Fig $1 \mathrm{a}$ to $\mathrm{c}$. Compared to the sample incubated under control conditions, the greatest differences were seen in the dark incubated samples, where only very minor changes in the 3 pigments were observed. Furthermore, although there was a net increase all 3 pigments in the presence of UV-B light, the increase in chl a was significantly lower than in the control samples. Chl $b$, on the other hand, appeared to be less susceptible to UV-B radiation and showed no systematic relationship with the amount of UV-B radiation. Carotenoids showed a marked increase in the presence of UV-B radiation.

At the end of $5^{\circ} \mathrm{h}$, when the UV-B lamps were switched off and the incubations were continued under PAR only, there was a general increase in the 3 pigments.

Fig. 1. Tetraselmis sp. Time-course of changes in concentrations of (a) chl $a$, (b) chl. $b$, and (c) carotenoids of cells growing under control conditions (PAR only), under UV-B light (UV-B + PAR) and in the dark during the short-term incubation experiment. UV-B radiation percentages represent fractions of the total $\left(19 \mu \mathrm{W} \mathrm{cm} \mathrm{cm}^{-2}\right)$ radiation that the cells were subjected to and were obtained by covering the UV-B-exposed sides of the incubation bottles with neutral density filters. Arrow indicates tume at which UV-B-treated and dark incubated samples were returned to control conditions 
Table 2. Tetraselmis sp. Effect of UV-B radiation on fatty acid composition of during the long-term incubation experiment. Preincubation and post-incubation (control) represent samples incubated under photosynthetically active radiation (PAR), whereas post-incubated (+UV-B) represents samples incubated under UV-B radiation $\left(19 \mu \mathrm{W} \mathrm{cm}^{-2}\right)$ plus PAR. Shown are means $\pm S D(n=$ 2 for pre-incubation samples and $n=4$ samples for post-incubation samples); values in parentheses are percentages of the total cellular fatty acid carbon

\begin{tabular}{|c|c|c|c|c|c|}
\hline Fatty acid & $\begin{array}{l}\text { Pre-incubation } \\
\mathrm{ng} \mathrm{C} \mathrm{ml}^{-1}(\%)\end{array}$ & $\begin{array}{c}\text { Post-incubation +UV-B } \\
\text { ng C ml-1 }(\%)\end{array}$ & $\begin{array}{l}\text { Post-incubation control } \\
\text { ng C m- })^{-1}(\%)\end{array}$ & $F_{(1.6)^{a}}$ & $p^{b}$ \\
\hline $14: 0$ & $1.46 \pm 0.06(1.2)$ & $2.28 \pm 0.06(1.8)$ & $2.14 \pm 0.03(1.07)$ & 12.3 & 0.01 \\
\hline I $15: 0$ & $0.22 \pm 0.01(0.18)$ & $0 \pm 0 \quad(0)$ & $0 \pm 0 \quad(0)$ & - & - \\
\hline A $15: 0$ & $0.32 \pm 0.01(0.26)$ & $0 \pm 0 \quad(0)$ & $0.4 \pm 0.04(0.2)$ & 1726 & 0 \\
\hline $15: 0$ & $0.74 \pm 0.01(0.61)$ & $1.36 \pm 0.06(0.07)$ & $0.72 \pm 0 \quad(0.36)$ & 1308 & 0 \\
\hline $16: 0$ & $27.2 \pm 0.23(22.3)$ & $44.5 \pm 5.8 \quad(35.1)$ & $50.6 \pm 3.55(25.4)$ & 8.71 & 0.03 \\
\hline $16: 1$ & $4.42 \pm 0.41(3.62)$ & $8.02 \pm 0.11(6.33)$ & $6.94 \pm 0.4 \quad(3.48)$ & 112 & 0 \\
\hline $17: 0$ & $0.72 \pm 0.06(0.59)$ & $1.34 \pm 0.04(1.06)$ & $0.8 \pm 0.07(0.4)$ & 167 & 0 \\
\hline $16: 2$ & $0.46 \pm 0.04(0.38)$ & $0 \pm 0 \quad(0)$ & $0.54 \pm 0.02(0.27)$ & 2423 & 0 \\
\hline $16: 3$ & $1.02 \pm 0.00(0.84)$ & $0 \pm 0 \quad(0)$ & $1.8 \pm 0.13(0.9)$ & 2114 & 0 \\
\hline $16: 4$ & $22.4 \pm 1.22(18.3)$ & $3.9 \pm 0.11(3.08)$ & $35.2 \pm 2.53(17.7)$ & 343 & 0 \\
\hline $18: 1(n-9)$ & $13 \pm 0.48(10.7)$ & $27.9 \pm 0.76(22.1)$ & $29.1 \pm 0.75(14.6)$ & 4.05 & 0.09 \\
\hline $18: 1(n-7)$ & $3.7 \pm 0.13(3.03)$ & $6.3 \pm 0.01$ & $6.7 \pm 0.25(3.36)$ & 1.86 & 0.22 \\
\hline $18: 2$ & $3.72 \pm 0.18(3.05)$ & $4.8 \pm 0.11(3.79)$ & $5.26 \pm 0.19(2.64)$ & 28.95 & 0 \\
\hline $18: 3(n-6)$ & $0.52 \pm 0.08(0.42)$ & $0 \pm 0 \quad(0)$ & $0 \pm 0$ & - & - \\
\hline $18: 3(n-3)$ & $26.3 \pm 1.68(21.6)$ & $23.9 \pm 0.57(18.9)$ & $38.8 \pm 1.75(19.4)$ & 5945 & 0 \\
\hline $20: 0$ & $0.32 \pm 0.06(0.26)$ & $0.84 \pm 0.03(0.66)$ & $0 \pm 0 \quad\{0\}$ & 9165 & 0 \\
\hline $18: 4$ & $3.38 \pm 0.18(2.77)$ & $0 \pm 0 \quad(0)$ & $6.62 \pm 0.05(3.32)$ & 23727 & 0 \\
\hline $18: 5$ & $1.38 \pm 0.14(1.13)$ & $0 \pm 0 \quad(0)$ & $1.9 \pm 0.09(0.95)$ & 4987 & 0 \\
\hline $20: 5$ & $10.8 \pm 0.27(8.85)$ & $1.42 \pm 0.01(1.12)$ & $11.9 \pm 2.73(6)$ & 118 & 0 \\
\hline Total & $122 \pm 5.15$ & $126.7 \pm 7.44$ & $199.5 \pm 12.16$ & 273 & 0 \\
\hline
\end{tabular}

\section{Fatty acids}

Long-term incubation experiment: cellular concentrations of component fatty acids

Exponentially growing cells of Tetraselmis sp. under control conditions exhibited a predominance of 16:0, 16:4, 18:1(n-9), and 18:3(n-3) (Table 2). Each of these acids accounted for over $10 \%$ of the total carbon within the fatty acid pool under control conditions. There was a minor presence (fatty acids accounting for less than $10 \%$ of the total carbon within the fatty acid pool) of $14: 0$, iso 15:0, anteiso 15:0, 15:0,16:1, 17:0, 16:2, 16:3, 18:1(n-7), 18:2, 18:3(n-6), 20:0,18:4, 18:5 and 20:5.

The absolute concentration of fatty acids in the samples incubated in the presence of UV-B radiation were much lower than in the control samples (Table 1). This reduction was attributable largely to the marked decline in the absolute concentrations of polyunsaturated fatty acids (PUFAs) (Tables $1 \& 2$ ).

Comparison of the absolute concentrations of the major fatty acids in the post-incubation samples (Table 2, Fig. 2), revealed that UV-B induced a significant reduction (below pre-incubation values), especially in the concentrations of the PUFAs 16:4 and 18:3(n-3). Variance ratios ( $F$-values in Table 2 ) enabled us reject the hypothesis that the differences in the absolute concentrations of component fatty acids between the control and UV-B-treated samples were not significant. The only fatty acids in which the differences between the control and UV-B-treated samples were insignificant at the 5\% level were $18: 1(n-9)$ and 18:1(n-7). The most unstable major fatty acid in the presence of UV-B was $16: 4$ as is obvious from its near complete disappearance in the post-incubation samples under UV-B light. Among the other major fatty acids, 16:0 and 18:1(n-9) appeared less susceptible to UV-B radiation than $16: 4$ and $18: 3(\mathrm{n}-3)$. Among the minor acids, a reduction to below pre-incubation values was observed in the absolute concentrations of $16: 2,16: 3,18: 3(n-6), 18: 4,18: 5$ and 20:5. Concentrations of $14: 0,15: 0,16: 1,17: 0$ and $20: 0$, on the other hand, were unaffected by UV-B radiation and were in fact higher than in the control samples.

In Table 2, data on absolute concentrations of component fatty acids are also expressed as percentages of the total fatty acid carbon. Differences in the percentage composition of fatty acids were very minor between pre- and post-incubation control samples. The relative composition of fatty acids in cells incu- 


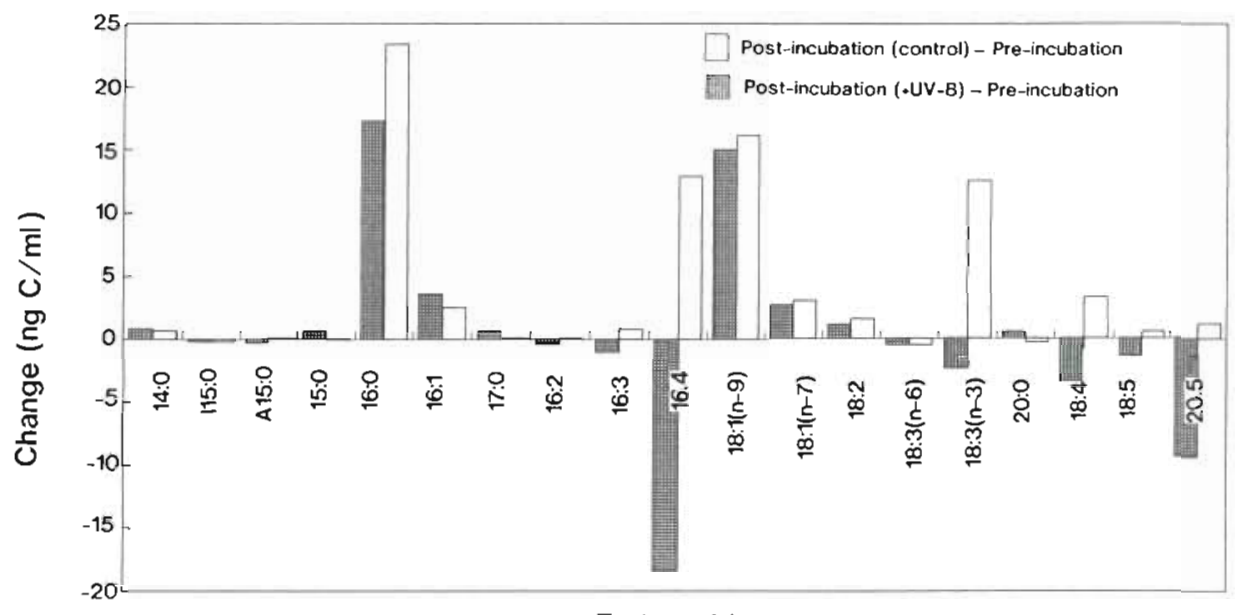

Fatty acid
Fig. 2. Tetraselmis sp. Changes in the absolute concentrations of component fatty acids in post-incubation control and UV-B-exposed (UV-B + PAR) samples at the end of the longterm incubation experiment

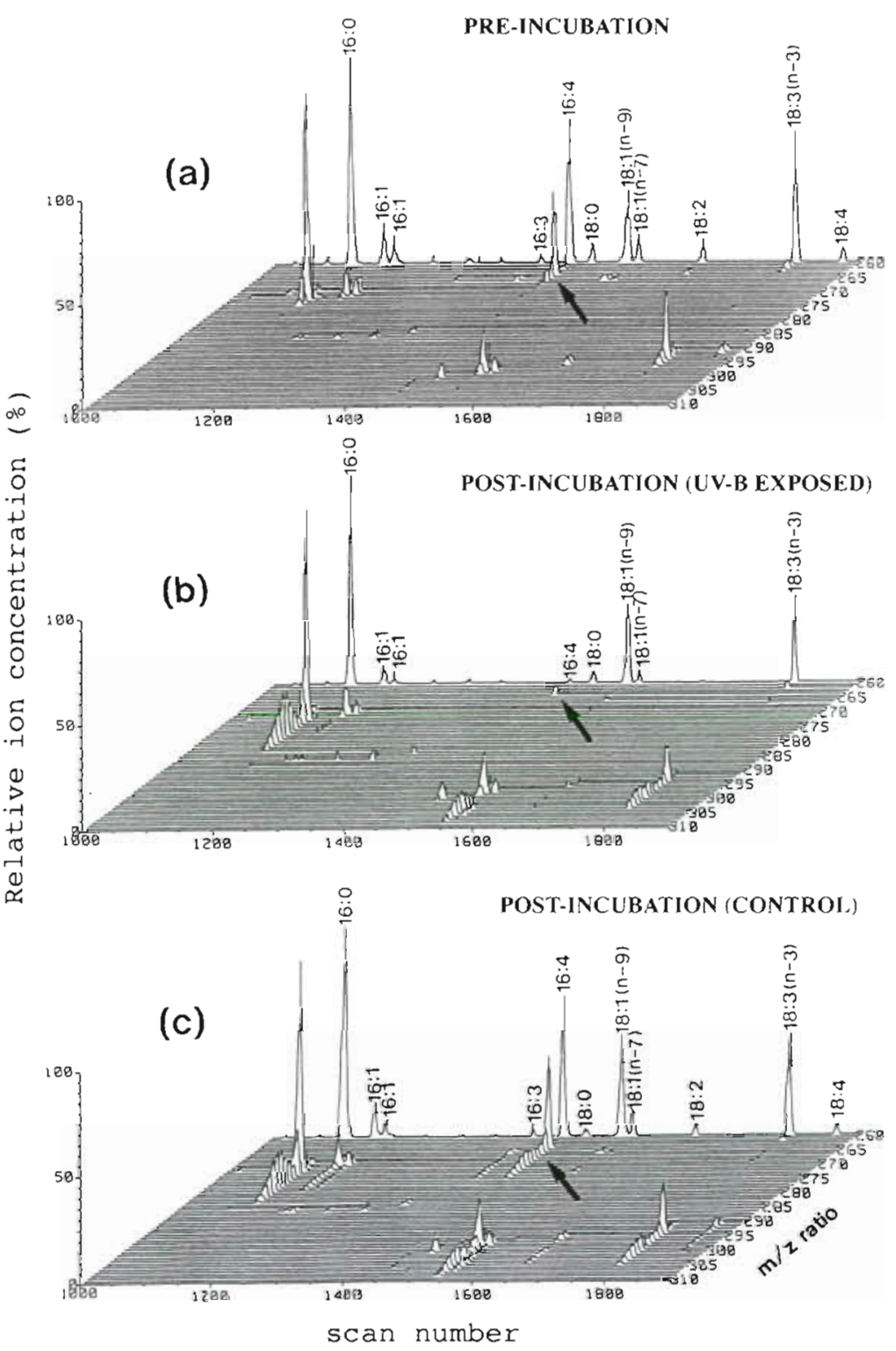

bated in the presence of UV-B, however, differed markedly from the pre-and postincubation control samples. Cells incubated in the presence of UV-B radiation were characterized by higher percentages of $16: 0,16: 1,18: 1(n-9)$ and $18: 1(n-7)$, attributable largely to the decline in the absolute concentrations of PUFAs within the cells.

Long-term incubation experiment:

${ }^{13} \mathrm{C}$ incorporation into component fatty acids

The 3-dimensional GC-MS chromatograms (note that these are only partial spectra of the entire chromatograms depicting mainly the major fatty acids) of pre- and post-incubation samples (Fig. 3a to c) depict the appearance of newly assimilated carbon among various cellular fatty acid components. Fig. 3a represents the pre-incubation samples (without addition of ${ }^{13} \mathrm{C}$ ). In Fig. $3 \mathrm{~b}$ and $\mathrm{c}$, due to assimilation of ${ }^{13} \mathrm{C}$ into the carbon

Fig. 3. Tetraselmis sp. Three-dimensional mass chromatogram (partial) of fatty acid methyl esters in: (a) pre-incubation, (b) postincubation UV-B exposed and (c) post-incubation control cells, depicting the incorporation of ${ }^{13} \mathrm{C}$ into the carbon skeletons of various fatty acids at the end of the long-term incubation experiment. Arrow has been drawn to highlight the differences in the mass chromatographic peaks of $16: 4$ in pre- and post-incubation samples 
skeleton of the fatty acids during incubation, it can be noticed that the ratios of the relative peak areas of the isotopic peaks for each acid (e.g. at $\mathrm{m} / 2$ $272,273,274, \ldots$, in the case of $16: 0$ ) to their quasi-molecular ion peaks (at $\mathrm{m} / \mathrm{z} 271$ for 16:0) are much higher in the post-incubation samples (with ${ }^{13} \mathrm{C}$ ) than in the pre-incubation samples (without ${ }^{13} \mathrm{C}$ ). For cells incubated in the presence of $U V-B$, however, this is only partially true, since UV-B completely inhibited the incorporation of ${ }^{13} \mathrm{C}$ into the fatty acids $16: 4$ (m/z 263, $264,265, \ldots$ indicated by arrows in Fig. $3 a$ to c), $18: 2$ and 18:4 but allowed incorporation into the other major acids (Fig. 3b).

Levels of production of individual fatty acids calculated from the GC-MS data and from the absolute concentrations of fatty acids obtained by GC are shown in Fig. 4a. Exposure to UV-B radiation resulted in a disproportionate production of some fatty acids as compared to the control sample. The highest production was observed for the fatty acid 16:0, which continued unabated even in the presence of UV-B and was slightly higher than in the control sample. UV-B completely suppressed the production of the fatty acids $16: 4,16: 3,18: 2,18: 4$ and 20:5. A reduction was also observed in the production of $16: 1,18: 1(n-7)$ and $18: 3$ $(n-3)$. As seen in Fig. $4 b_{\text {, in the pres- }}$ ence of UV-B light, the production of 16:0 accounted for over $50 \%$ of the total ${ }^{13} \mathrm{C}$ incorporated into the fatty acid pool. Under control conditions, the percentage distribution of newly assimilated carbon into the major fatty acids varied within a very narrow range (between 17 and $25 \%$ of the total carbon assimilated).

Short-term incubation experiment:

time course of changes in absolute concentrations of component fatty acids

During the short-term incubation experiment, although the absolute concentrations of total fatty acids increased in the presence of UV-B light and in the dark, these rates were much lower compared to those of the cells incubated under control conditions (Fig. 5a). In the presence of UV-B light, no systematic relationship was discernible between the increase of total fatty acids and UV-B radiation levels. In the dark, the minor increase in total fatty acids was attributable largely to the increase in the concentrations of the saturated acids 14:0 and 16:0, which accounted for a major fraction of the cellular fatty acids formed at the end of 300 min incubation in the dark (Table 3). In the dark-incubated samples, it was noted that except for the fatty acid 15:0, the concentrations of all fatty acids were lower than those observed in the pre-incubation cells. In contrast, in the presence of UV-B radiation, the slow increase in fatty acid concentrations could be attributed largely to the reduction in absolute concentrations of PUFAs which began as early as $120 \mathrm{~min}$ after incubation.

The time course of changes in the absolute concentrations of some of the major component fatty acids during the short-term incubation experiment is shown in Fig. $5 \mathrm{~b}$ to $\mathrm{f}$. A detailed inventory of changes in the cellular fatty composition of samples incubated for 

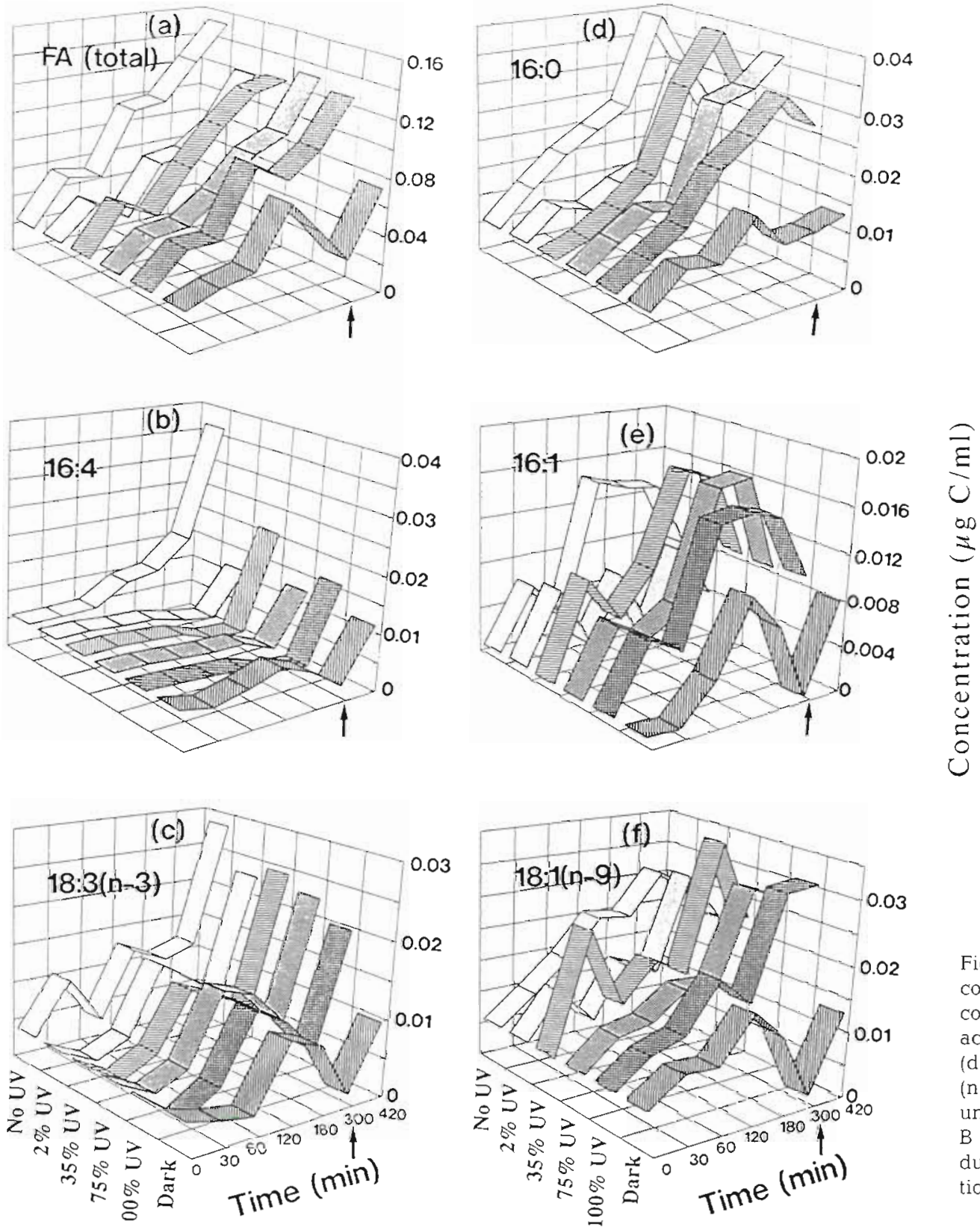

Fig. 5. Tetraselmis sp. Time course of changes in cellular concentrations of (a) total fatty acids, (b) $16: 4$, (c) $18: 3(\mathrm{n}-3)$, (d) 16:0, (e) 16:1, and (f) 18:1 $(n-9)$ in cells growing solely under PAR, in presence of UV$B$ radiation and in the dark during the short-term incubation experiment. Other detals as in Fig. 1

$300 \mathrm{~min}$ in the presence of UV-B radiation $1100 \%$ UV-B + PAR), in the dark, under control conditions and during the return to control conditions at the end of 420 min is presented in Table? 3. It can be easily observed that among the major PUFAs, 16:4 was the least stable fatty acid in the presence of UV-B radiation and it increased only in cells growing under control conditions (Fig. 5b, Table 3) The other major unsaturated fatty acid, $18: 3(n-3)$, was less sensitive to UV-B (Fig. 5c); however, its absolute concentration showed a decline at the end of $300 \mathrm{~min}$ of incubation under UV-B light. The major fatty acids $16: 0$ and 18:1(n-9)
(Fig. $5 \mathrm{~d}$ and $\mathrm{f}$ respectively) and most of the other minor saturated and monounsaturated fatty acids, for example 16:1 (Fig. 5e), showed a general increase when grown under UV-B light. An analysis of variance was performed to test the hypothesis that there were no significant differences in the absolute concentrations of the total and component fatty acids (1) between the control and various treatments and (2) between the treatments themselves. This analysis did not include the time 0 values or the values of fatty acids recorded when the treated samples were returned to control conditions. Variance ratios $(F)$ presented in Table 4 
Table 3. Tetraselmis sp. Fatty acid composition at time 0 and at the end of $300 \mathrm{~min}$ of incubation under $100 \%$ UV-B light l(19 $\mu \mathrm{W}$ $\mathrm{cm}^{-2}$ UV-B) + PAR (photosynthetically active radiation)], under dark and under control (PAR) conditions during the short-term experıment. At the end of 300 min all the samples were transferred to control conditions and the incubations were continued for another $120 \mathrm{~min}$ in order to study changes in the fatty acid composition of the cells during this period of recovery. Concentrations of fatty acids are in $\mathrm{ng} \mathrm{m}^{-1}$ Values in parentheses are percentages of the total cellular fatty acid carbon

\begin{tabular}{|c|c|c|c|c|c|c|c|}
\hline \multirow[t]{2}{*}{ Fatty acid } & \multirow{2}{*}{ Time 0} & \multicolumn{2}{|c|}{$100 \%$ UV-B + PAR } & \multicolumn{2}{|c|}{ Dark } & \multicolumn{2}{|c|}{ Control } \\
\hline & & $300 \mathrm{~min}$ & $420 \mathrm{~min}$ & $300 \mathrm{~min}$ & $420 \mathrm{~min}$ & $300 \mathrm{~min}$ & $420 \mathrm{~m} ı n$ \\
\hline $14: 0$ & $0.24(0.98)$ & $1.69(1.81)$ & $2.03(1.62)$ & $11(40.5)$ & $1.03(1.44)$ & $3.4(2.7)$ & $1.83(1.22)$ \\
\hline J. $15: 0$ & $0.04(0.15)$ & $0(0)$ & $0(0)$ & $0(0)$ & $0(0)$ & $0(0)$ & $0(0)$ \\
\hline A $15: 0$ & $0.05(0.22)$ & $0(0)$ & $0(0)$ & $0(0)$ & $0(0)$ & $0.87(0.69)$ & $0(0)$ \\
\hline $15: 0$ & $0.12(0.50)$ & $2.09(2.24)$ & $1.03(0.82)$ & $0.67(2.47)$ & $0(0)$ & $1.38(1.1)$ & $0(0)$ \\
\hline $16: 0$ & $5.86(23.7)$ & $32(34.3)$ & $26.1(20.8)$ & $11.2(41.1)$ & $12.8(17.9)$ & $39.4(31.4)$ & $30.1(20)$ \\
\hline $16: 1$ & $2.13(8.61)$ & $14.4(15.4)$ & $8.77(6.99)$ & $0(0)$ & $7.83(10.9)$ & $13.3(10.6)$ & $7.43(4.93)$ \\
\hline $17: 0$ & $0(0)$ & $0(0)$ & $O(0)$ & $0(0)$ & $0(0)$ & $1.27(1)$ & $0(0)$ \\
\hline $16: 2$ & $0.08(0.31)$ & $0(0)$ & $0(0)$ & $0(0)$ & $0(0)$ & $0(0)$ & $0(0)$ \\
\hline $16: 3$ & $0.17(0.69)$ & $0(0)$ & $0(0)$ & $0(0)$ & $0(0)$ & $4.12(3.3)$ & $0(0)$ \\
\hline $16: 4$ & $4.03(16.3)$ & $2.48(2.66)$ & $15.7(12.5)$ & $2.05(7.6)$ & $11.1(15.5)$ & $16(12.8)$ & $32.9(21.8)$ \\
\hline $18: 0$ & $0.48(1.94)$ & $0(0)$ & $3.23(2.58)$ & $0(0)$ & $2.03(2.83)$ & $1.12(0.89)$ & $0(0)$ \\
\hline $18: 1(n-9)$ & $5.83(23.6)$ & $29.7(31.8)$ & $30.2(24.1)$ & $1.15(4.24)$ & $12.6(17.5)$ & $26.3(21)$ & $23.1(15.3)$ \\
\hline $18: 1(n-7)$ & $0.31(1.24)$ & $4.87(5.21)$ & $O(0)$ & $0(0)$ & $1.8(2.51)$ & $0(0)$ & $0(0)$ \\
\hline $18: 2$ & $0.31(1.25)$ & $1.38(1.48)$ & $4.37(3.48)$ & $0(0)$ & $1.9(2.6)$ & $2.22(1.77)$ & $3.97(2.63)$ \\
\hline $18: 3(n-6)$ & $0.10(0.39)$ & $O(0)$ & $1.7(1.36)$ & $0(0)$ & $0(0)$ & $0(0)$ & $0(0)$ \\
\hline $18: 3(n-3)$ & $4.37(17.7)$ & $4.77(5.11)$ & $19.6(15.6)$ & $1.14(4.22)$ & $9.47(13.2)$ & $12.4(9.83)$ & $28.3(18.7)$ \\
\hline $20: 0$ & $0(0)$ & $0(0)$ & $O(0)$ & $0(0)$ & $0(0)$ & $0(0)$ & $0(0)$ \\
\hline $18: 4$ & $0.31(1.24)$ & $0(0)$ & $5.57(4.44)$ & $0(0)$ & $3.63(5.06)$ & $2.77(2.21)$ & $5.97(3.96)$ \\
\hline $18: 5$ & $0.14(0.58)$ & $0(0)$ & $1.4(1.12)$ & $O(0)$ & $1.03(1.44)$ & $0.44(0.35)$ & $6.33(4.2)$ \\
\hline $20: 4$ & $0(0)$ & $0(0)$ & $0.0(0)$ & $0(0)$ & $0(0)$ & $0(0)$ & $0(0)$ \\
\hline $20: 5$ & $0.14(0.57)$ & $0(0)$ & $5.67(4.52)$ & $0(0)$ & $6.53(9.1)$ & $0.57(0.45)$ & $10.9(7.23)$ \\
\hline Total & $24.7(100)$ & $93.5(100)$ & $125.4(100)$ & $27.1(100)$ & $71.8(100)$ & $125.6(100)$ & $150.8(100)$ \\
\hline
\end{tabular}

indicate that the differences in the concentrations of total fatty acids between the control and various UV-B treatments were not significant. For most of the individual fatty acids examined, except for 16:4, the differences between the control and various UV-B treatments were not significant. Likewise, the differences between the dark and UV-B-treated samples were also not significant. Between the control and dark samples the differences were significant for total fatty acids, 16:4 and 18:1. The lack of significant differences between the control and UV-B-treated samples for the short-term incubation experiment contrasts with the results of the long-term incubation experiment. Although differences in the concentrations of component fatty acids between various samples were quite conspicuous at the end of $300 \mathrm{~min}$ of incubation, it is

Table 4. Variance ratios $(F)$ and significance levels $(p)$ obtained from analysis of variance performed on the short-term incubation samples to provide a measure of the differences in the mean concentrations of total and component fatty acids between control and treated samples. Fatty acid data at time 0 and at the time treated samples were transferred to control conditions have not been included in this analysis

\begin{tabular}{|c|c|c|c|c|c|c|}
\hline \multirow{3}{*}{ Fatty acid } & \multicolumn{6}{|c|}{ Source of variation } \\
\hline & \multicolumn{2}{|c|}{$\begin{array}{l}\text { Between control and UV-B } \\
\text { treatments }(\mathrm{df}=4, \mathrm{n}=20)\end{array}$} & \multicolumn{2}{|c|}{$\begin{array}{l}\text { Between UV-B treatments } \\
\qquad(\mathrm{df}=3, \mathrm{n}=16)\end{array}$} & \multicolumn{2}{|c|}{$\begin{array}{l}\text { Between control and dark } \\
\text { treatments }(\mathrm{df}=1, \mathrm{n}=8 \text { ) }\end{array}$} \\
\hline & $F$ & $\mathrm{p}$ & $F$ & $\mathrm{p}$ & $F$ & $\mathrm{p}$ \\
\hline Total & 0.76 & 0.57 & 0.46 & 0.71 & 6.13 & 0.04 \\
\hline $16: 4$ & 5.83 & 0.003 & 0.20 & 0.90 & 4.85 & 0.06 \\
\hline $18.3(n-3)$ & 0.78 & 0.55 & 0.07 & 0.93 & 4.96 & 0.06 \\
\hline $16: 0$ & 0.29 & 0.88 & 0.27 & 0.85 & 4.77 & 0.06 \\
\hline $16: 1$ & 1.34 & 0.29 & 1.83 & 0.18 & 3.60 & 0.09 \\
\hline $18: 1(n-9)$ & 0.38 & 0.82 & 0.43 & 0.74 & 5.77 & 0.04 \\
\hline $20: 5$ & 1.78 & 0.17 & 0.44 & 0.73 & 0.82 & 0.39 \\
\hline
\end{tabular}


possible that the observed lack of significant differences between UV-B treatments and control samples could have been influenced by the minor differences in the concentrations of most fatty acids between various samples during the early part of the short-term incubation experiment. These results do show, however, that 16:4 was the fatty acid most sensitive to UV-B radiation. On the other hand, most of the other component fatty acids of Tetraselmis sp. were less sensitive to UV$B$ radiation and seemed to be dependent on the total UV-B radiation dose (dosage rate $x$ time of exposure) to which the cells were exposed.

When the UV-B lamps were switched off at the end of $300 \mathrm{~min}$ and the incubation was continued under control conditions for another $120 \mathrm{~min}$, the percentage composition of the saturated and monounsaturated fatty acids in the fatty acid pool declined (Table 3), largely due to a dramatic increase in the absolute concentrations of several PUFAs [see Fig. 5b, c depicting the PUFAs 16:4 and 18:3(n-3)]. In the samples previously incubated in the dark, transfer to control conditions resulted in a decrease in the percentages of the saturated fatty acids $14: 0$ and $16: 0$ and a marked change in the overall cellular fatty acid composition (Table 3).

\section{DISCUSSION}

The present set of experiments on Tetraselmis $\mathrm{sp}$. demonstrates that the presence of UV-B radiation during photosynthesis induces considerable changes in cellular mechanisms related to production of pigments and fatty acids. As noted in the case of some fatty acids, these changes could occur over very short periods, indicating the unique capability of Tetraselmis. sp. to rapidly reorganize cellular processes, presumably as part of its adaptive response for growth optimization and survival under UV-B radiation. Interestingly, this organism also showed a remarkable capacity for recovery from the stressful effects of UV-B when transferred back to control conditions.

\section{Effect of UV-B radiation on pigments}

Exposure to UV-B radiation induced a rapid increase in carotenoids (Fig. 1C) and the carotenoid: chl a ratio (Table 1) within the culture suspension. This increase related well with the amount and period of exposure to UV-B light during the experiment. Our results on the effects of UV-B on chl a are in agreement with those of Dohler (1984), but differ from his observations on carotenoids, which he also found to decrease in the presence of UV-B radiation. The results of Dohler
(1984) which were based on 2 organisms belonging to the class Bacillariophyceae, did however show interspecies differences in response to UV-B. Dohler (1984) also showed that the presence of other stress factors during incubation markedly influenced the pigment composition of the organisms. In the present study, except for UV-B radiation, Tetraselmis sp. was under no additional stress. The discrepancy between our results and those of Dohier (1984) thus seems most likely due to differences in species response.

The rapid increase in carotenoids possibly represents a photoadaptive response against UV-B radiation, as a major fraction of the pigments belonging to this group are photoprotective in nature and have been reported to prevent degradation of the chloroplast in cells subject to very high light intensities (Falkowski 1980, Prezelin 1981, Ben-Amotz \& Avron 1989). It is also possible, therefore, that the rapid synthesis of carotenoids could have sustained the increase in chl a that was observed during the early part of the incubation under UV-B radiation (Fig. 1a).

\section{Effect of UV-B radiation on cellular fatty acid composition}

As has been demonstrated in several other green algae (Pohl 1974, Ben-Amotz et al. 1985), Tetraselmis sp. contained a higher proportion of the saturated fatty acid 16:0, the monounsaturated acid 18:1(n-9) and the polyunsaturated fatty acids $16: 4$ and 18:3(n-3). Except for iso and anteiso 15:0, the fatty acid composition of Tetraselmis sp. cells growing under control conditions (Table 2) is in conformity with earlier observations on fatty acids in this organism (Ackman et al. 1968). Although branched isomers of 15:0 have been reported in marine phytoplankton (DeMort et al. 1972) they are predominantly of bacterial origin (Volkman et al. 1989). In phytoplankton cultures, their presence may help provide a quick estimate of bacterial contamination (Volkman et al. 1989). If so, bacterial contamination in our experimental culture appears to have been negligible. The absence of newly assimilated carbon in this fraction at the end of the long term incubation experiment seems to reinforce the view that these branched isomers were of bacterial origin. Again, if these isomers were of bacterial origin, it of interest to note that their apparent absence in the cultures exposed to UV-B radiation during the long- and shortterm incubation experiments (these changes were observed at as early as 300 min during the short incubation experiments), probably indicates that marine bacterial cells completely lack protective mechanisms against UV-B radiation, as suggested by Herndl et al. (1993). During their observations on natural popula- 
tions of marine bacteria, Herndl et al. (1993) also noted that UV-B considerably reduced bacterial enzyme activity and growth, and on this basis, they concluded that UV-B radiation enhancement in nature could have a tremendous impact on biogeochemical processes in the sea. Our results suggest that such an impact on biogeochemical cycles in the sea could be compounded even further by the effect of UV-B radiation on phytoplankton-bacterial interactions.

Cells growing under control conditions invariably had the highest rates of fatty acid production. In the dark, fatty acid concentrations rose very slowly, but increased rapidly when transferred to control conditions, emphasizing the requirement of optimal light conditions for fatty acid production. In earlier studies, Harris et al. (1965) and Huang \& Stumpf (1971) observed that light during photosynthesis stimulates fatty acid synthesis by increasing the supply of cofactors. They also noted that the absence of light led to a decline but not complete inhibition of fatty acid synthesis, which is in accordance with our observations on dark incubated samples. In separate studies, Hellyer et al. (1986) and Harwood (1988) noted that acetyl-cocarboxylase (ACCase), an important enzyme in fatty acid synthesis, was dependent on ATP produced during light reactions of photosynthesis. In the dark, limited availability of ATP could have significantly diminished the activity of this enzyme, resulting in lowered rates of fatty acid production within the cells (Fig. 5a).

The supply of ATP can also have a major influence on the composition of fatty acids formed during photosynthesis, according to Thompson et al. (1990). These authors noted that during fatty acid biosynthesis, the process of chain elongation and unsaturation requires a large amount of ATP compared to that required for the production of saturated and monounsaturated fatty acids. Thus it seems likely that a limited supply of ATP was probably the cause for decline in the concentrations of all the long-chain unsaturated fatty acids.

Concentration of component fatty acids increased under UV-B light but at a much slower pace than in the control sample. Although UV-B is known to denature enzymes (Iwanzik et al. 1983, Dohler 1985), such a possibility with respect to the enzyme ACCase, the enzyme involved in synthesizing the primary fatty acids (14:0, 15:0 and 16:0) (Benson 1966), seems highly unlikely as there was a continuous appearance of carbon tracer and production of these fatty acids even in the presence of UV-B radiation. Unlike cells growing in the dark, however, where the absence of light led to a disproportionate but slow rate of increase of 14:0, 15:0 and 16:0 and a decrease in the absolute concentrations of almost all the other component fatty acids (Table 3), in the presence of UV-B radiation the dimin- ished rate of fatty acid production resulted largely from a selective reduction of carbon assimilation into PUFAs (Figs. $3 \& 4 a, b$ ) and a reduction in the absolute concentrations of these components (Tables 1 to 3 ). Since UV-B radiation restricts (but does not completely inhibit) ATP production (Vosjan et al. 1990), this reduction in the supply of ATP could probably account for the selective decline in the production of PUFAs in cells incubated under UV-B radiation. A general decline in the proportion of saturated and monounsaturated fatty acids and a rapid increase in the proportion of PUFAs within the cells when the UV-B lamps were switched off seems to support this view.

The greater proportion of ${ }^{13} \mathrm{C}$ assimilation into the fatty acid 16:0 under UV-B radiation and in the dark (Tables 2 \& 3, Figs. 3b \& 4a, b) supports the view of Pohl \& Wagner (1972) that the biosynthesis of this fatty acid is independent of light, and that of Roessler (1990) who noted that 16:0 could actually represent an energy source during production under unfavorable growth conditions. In addition to 16:0, storage lipids of phytoplankton are generally made up of short-chain saturated and monounsaturated fatty acids (Benson 1966, Roessler 1990), the concentrations of which were generally unaffected by UV-B radiation during the present study (Tables $2 \& 3$, Figs. $2 \& 5 d$ to f). According to Roessler (1990) these compounds are rapidly utilized when growth conditions improve, which agrees with our observations of a rapid decline in the concentrations of saturated and monounsaturated fatty acids when the cells growing under UV-B radiation and in the dark were returned to control conditions (Fig. 5b to f). These observations also support the view that saturated and monounsaturated fatty acids could be the precursors of long-chain PUFAs (Siron et al. 1989).

In the control sample, the increase in the relative content of cellular PUFAs shows that their biosynthesis takes place mainly under optimal conditions, during the phase of intense cellular activity, confirming their active role in photosynthesis (Siron et al. 1989). In general, the rapid increase in cellular concentrations of PUFAs in metabolically active cells growing under optimum light conditions has been linked to an ample supply of oxygen during photosynthesis, as oxygen has been shown to be a necessary co-factor for synthesis of PUFAs (Nichols \& James 1968), Although PUFAs are not involved chemically in photosynthesis (Nichols \& James 1968), it has been proved that their formation facilitates the light reactions of photosynthesis (Opute 1974), via molecular orientation and spacing of the chlorophyll molecules in the membranes (Benson 1966, Kates \& Volcani 1966). It is also believed that an increase in PUFAs represents a need for greater unsaturation at higher rates of photosynthesis (Costantopoulous \& Bloch 1967). 

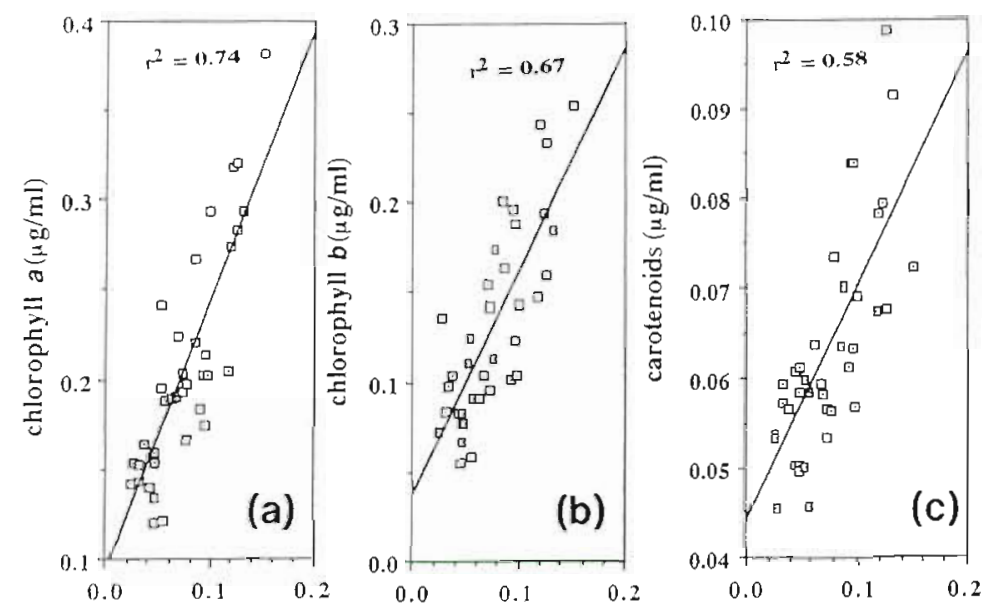

Fatty acids (total) $(\mu \mathrm{g} \mathrm{C} / \mathrm{ml})$

Fig. 6. Tetraselmis sp. Relationship between cellular concentrations of total fatty acids and (a) chl $a$, (b) chl b and (c) carotenoids. Data from shortterm incubation experiment

\section{Relationship between fatty acids and pigments}

The increase in concentrations of fatty acids under all conditions related well with the increase in the amount of chl $a$ and chl $b$ (Fig. 6a, b), suggesting $a$ strong association between these components. The relationship between fatty acids and carotenoids was, however, not very robust (Fig. 6c). Our studies revealed that there was a close coupling between concentrations of the PUFAs, which consisted mainly of 16:4 and 18:3(n-3), and chl a (Fig. $7 \mathrm{a}$ and b respectively). These 2 acids are located principally in the monogalactosyl diglyceride lipid fraction and account for about $90 \%$ of the total lipid content of chloroplast

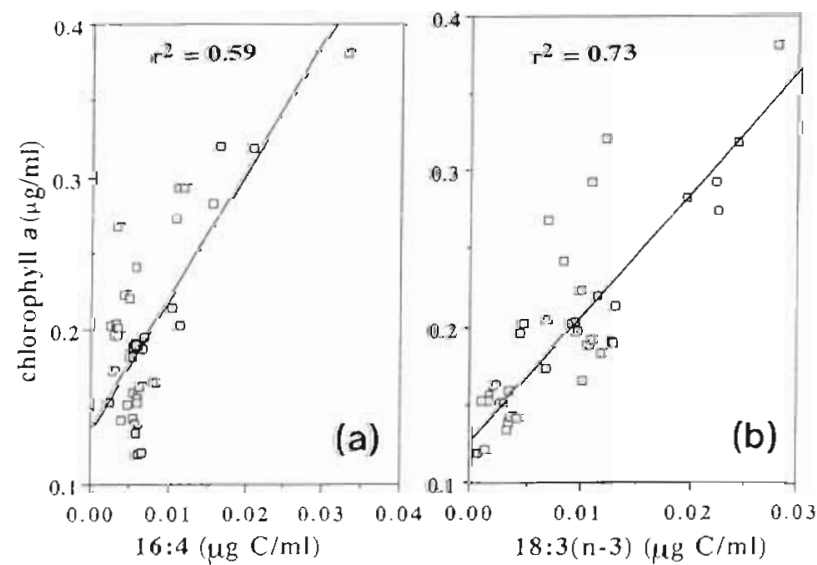

Fig. 7 Tetraselmis sp. Relationship between (a) 16:4 and chla. (b) 18:3(n-3) and chl a. Data from short-term incubation experiment membranes in green algae (Rosenberg \& Gouaux 1967. Ackman et al. 1968, Goldberg \& Ohad 1970, Kates 1972, Opute 1974, Pohl \& Wagner 1972, Forde \& Steer 1976, Fuller \& Nes 1987). In the present study, the relationship between the fatty acid 18:3(n-3) and chl a was more significant than that between 16:4 and chl a. The fatty acid 18:3(n-3) appeared to be less susceptible to UV-B radiation, probably because a small amount of $18: 3(n-3)$ can be formed via a light-independent pathway (Pohl \& Wagner 1972), and it could have accounted for the continued increase in chl a that we observed even in the presence of UV-B radiation. The rapid increase in chl $a_{\text {, the decline }}$ in saturated and monounsaturated acids and the increase in the concentration of these PUFAs during the short-term experiment when the cells were returned to control conditions thus confirms: (1) that saturated and monounsaturated fatty acids provide the energy required for rebuilding of the photosynthetic apparatus when growth conditions improve; and (2) that PUFAs are essential for chlorophyll membrane development (Harwood \& Russell 1984, Ben-Amotz \& Avron 1989, Siron et al. 1989, Roessler 1990, Thompson et al. 1990). On the basis of our results, it seems reasonable to suggest that UV-B radiation influences chloroplast membrane synthesis through its control of the production of these 2 acids

\section{Effect of UV-B radiation on the PUFA 16:4 and a hypothesis for its selective suppression}

Of the 2 major unsaturated fatty acids in Tetraselmis $\mathrm{sp}, 16: 4$ was much more sensitive to UV-B radiation than 18:3(n-3) since its concentration declined rapidly when the cells were exposed to UV-B light during the short-term incubation experiment. A $3 \mathrm{~h}$ incubation period under UV-B radiation, irrespective of the dosage rate or total dose during the experiment, led to a near complete reduction in the absolute concentrations of 16:4. These observations, as well as those which showed a rapid increase in the absolute concentrations of this acid when the UV-B lamps were switched off and the incubations were continued under control conditions, prove that UV-B radiation suppresses the synthesis of this acid. We observed a near complete disappearance of 16:4 from the fatty acid pool in the presence of UV-B radiation in the long term incubation as well. The complete absence of labeled carbon in 16:4 at the end of $12 \mathrm{~h}$ under UV-B light (Figs. $3 b$ \& $4 \mathrm{a}, \mathrm{b}$ ) also substantiates the view that UV-B 
suppresses the synthesis of this major fatty acid in Tetraselmis sp. The suppression of 16:4 and of PUFA synthesis in general by UV-B radiation plus the inability of the cells to produce these compounds in the dark suggests that over a diel cycle in the natural environment, if the production of PUFAs is suppressed by UV$B$ radiation during the day, phytoplankton cells may be unable to restore the cellular balance of these compounds at night. Under control conditions, the increase in concentration of $16: 4$ throughout the experiment and the uninterrupted increase in chl a during this period reinforces the view that this acid is highly susceptible to UV-B radiation and is closely related to formation of the chloroplast.

As can be seen in Fig. 8, desaturation of the fatty acid $16: 0$ was highly dependent on the dose of UV-B radiation and therefore seems to be a useful indicator of UV$B$ stress. In this scatter diagram, the accumulation of points along the dependent axis at lower UV-B radiation doses may be attributable to the continued accumulation of 16:4 during the early part of the incubation when carotenoid pigments were actively functioning as photoprotective pigments (Falkowski 1980, Prezelin 1981, Ben-Amotz \& Avron 1989).

The manner in which UV-B selectively suppresses 16:4 is not very clear, but in several green microalgae growing under optimum light, it has been reported that a deficiency of a nitrogen source in the medium can selectively suppress the production of $16: 4$ and 18:3(n-3) (Pohl \& Wagner 1972, Pohl 1974). In our experimental cultures, nitrate was the main source of

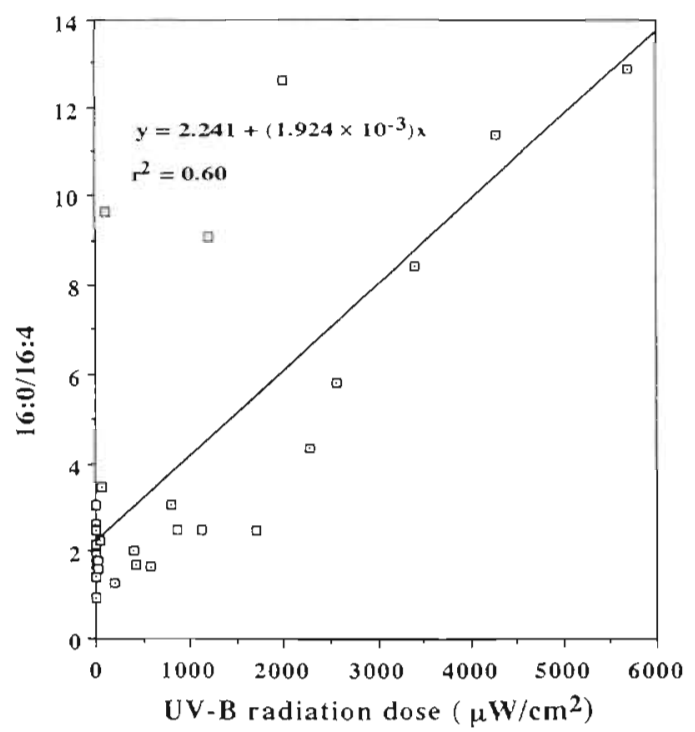

Fig. 8. Tetraselmis sp. Relationship between UV-B radiation dose (dosage rate $\times$ time of exposure) and cellular carbon weight ratio of $16: 0$ to 16:4. Data from short-term incubation experiment nitrogen and its concentration was never limiting in the medium. Our experimental culture was also found to grow well with nitrate as the sole nitrogen source, indicating that nitrate reductase was an active enzyme of nitrate assimilation in this organism. However, other studies have indicated that UV-B radiation can have a deleterious effect on nitrate assimilation into the cells by restricting ATP production, which is an essential requirement for nitrate reduction by nitrate reductase (Dohler et al. 1987, 1991, Dohler 1990, 1992). In some species, Dohler and his co-workers noted further that UV-B radiation could directly denature nitrate reductase. It thus seems likely that incubation of the cells under UV-B could have induced nitrogen limitation within the cells via either one or both of the above processes, leading to a reduction in 16:4 biosynthesis.

In Dohler et al. (1991), in addition to its deleterious influence on nitrate reductase, it was observed that UV-B had a significant negative effect on several key enzymes involved in nitrogen metabolism, which restricted protein biosynthesis and led to accumulation of amino acids within the cells. Among the amino acids, it was seen that UV-B induced a rapid accumulation of glutamine, a compound whose presence in large amounts in the cell was shown to suppress nitrate reduction and nitrate assimilation within the cells (Rigano et al. 1981).

It is interesting to note that the observed reduction of 16:4 under UV-B radiation closely resembles the response of this acid in cells of Euglena gracilis treated with the photosynthetic inhibitor dichloromethyl urea (DCMU) (Pohl \& Wagner 1972). In addition to 16:4, DCMU was also found to suppress the synthesis of 18:3(n-3) and chl a. Such a discrepancy in response between DCMU and UV-B treated cells can also be noted in the photosynthetic rates, which were completely inhibited by DCMU but continued under exposure to UV-B radiation. Whilst DCMU completely blocks photosynthesis by stopping electron flow between photosystems I and II of the chloroplast, UV-B radiation gradually damages photosystem II (Renger et al. 1989) and may be the probable reason for differences in fatty acid suppression and chloroplast production between DCMU-treated and UV-B-exposed cells.

\section{Implications of UV-B radiation enhancement on the marine food chain and biogeochemical cycles in the sea}

In addition to $16: 4$ and 18:3, UV-B radiation also suppressed the production of some other PUFAs, i.e. 20:5, $16: 3,18: 4$ and $18: 5$. The fatty acid $20: 5$ is associated with structural lipids of the cell membrane (Claustre et al. 1989). Its suppression by UV-B radiation reveals that 
UV-B enhancement in the environment could limit renewal of cellular structures and thus growth of phytoplankton. It has been shown that a decrease in the proportion of PUFAs within phytoplankton can reduce membrane permeability and thereby hamper nutrient assimilation and growth of phytoplankton (Claustre et al. 1989), which is in addition to the direct effect of UV-B radiation on certain enzymes involved in nutrient assimilation (Dohler et al. 1991 and references cited therein). In the natural environment, therefore, by restraining nutrient uptake in phytoplankton, the presence of UV-B radiation during the onset of a phytoplankton bloom could impede growth and formation of blooms even under conditions of plentiful nutrients.

In the natural environment, although fatty acids constitute a small proportion of the total organic matter synthesized by marine algae (Hama \& Handa 1987, Hama 1988, 1991), they represent an important source of energy for marine trophic food chains. Their importance is qualitative since certain phytoplanktonic fatty acids are essential for higher trophic levels (Siron et al. 1989). As has been demonstrated in many studies, a dietary deficiency of PUFAs in phytoplankton can limit the growth of several herbivores (Watanabe et al. 1983, Arnott et al. 1986, Huntley et al. 1987, Volkman et al. 1989). In the marine environment such an impact of UV-B radiation on the biochemical status of phytoplankton could thus have serious consequences on the food chain (Claustre et al. 1989).

\section{CONCLUSIONS}

The accumulation of saturated and monounsaturated fatty acids and the decline in PUFA synthesis amply demonstrate that UV-B radiation, when present at intensities that still permit the assimilation of carbon within the cells, can induce changes in phytoplankton lipid biochemistry through its effect on fatty acid biosynthesis. These changes can have an effect on material cycling in the sea and on marine biogeochemical processes. While the present experiments have been limited to 1 species of phytoplankton, it is possible that the negative effects of UV-B on PUFAs that we observed will motivate further research on this subject in a wider range of phytoplankton. The selective suppression of PUFA synthesis, in particular 16:4 in green algae, in proportion. to the dose of UV-B radiation seems a promising indicator of growth under UV-B stress. Although the relationship between the ratio of 16:0 to $16: 4$ and UV-B radiation dose is only empirical, it is hoped that this observation will stimulate further studies to confirm the usefulness of fatty acid unsaturation indices as indicators of UV-B-induced physiological stress in marine phytoplankton.
Acknowledgements. This study was supported by the Ministry of Education (Monbusho), Japan. A scholarship from Monbusho to J.I.G. is gratefully acknowledged. We are grateful to Dr H. Saito from the Hokkaido National Fisheries Institute for his help during this work and to Dr K. Furuya (Japan) and Prof, G. Dohler for suggesting improvements to an earlier version of this manuscript.

\section{LITERATURE CITED}

Ackman, R. G., Tocher, C. S., MacLachlan, J. (1968). Marine phytoplankter fatty acids. J. Fish. Res. Bd Can. 25: $1603-1620$

Arnott, G. H., Brand, G. W., Kos, L. C. (1986). Effects of food quality and quantity on the survival, development and egg production of Gladiofereus pectinatus Brady (Copepoda: Calanoida). Aust. J. mar. Freshwat. Res. 37: 467-473

Ben-Amotz, A., Avron, M. (1989). The wavelength dependence of massive carotenoid synthesis in Dunaliella baradwil (Chlorophyceae). J. Phycol. 25: 175-178

Ben-Amotz, A., Tornabene, T. G., Thomas, W. H. (1985). Chemical profile of some selected species of microalgae with emphasis on lipids. J. Phycol. 21: 72-81

Benson, A. A. (1966). On the orientation of lipids in chloroplast and cell membranes. J. Am. Oil Chem. Soc. 43: $265-270$

Caldwell, M. M. (1981). Plant response to solar ultraviolet radiation. In: Lange, O. L., Nobel, P. S., Osmond, C. B., Zeigler, H. (eds.) Encyclopaedia of plant physiology, Vol. 12a, Physiological plant ecology, Part I. Springer-Verlag, Berlin, p. 169-197

Calkins, J., Thordardottir, T (1980). The ecological significance of solar UV radiation on aquatic organisms. Nature 283: $563-566$

Claustre, H., Marty, J., Cassiani، L. (1989). Intraspecific differences in the biochemical composition of a diatom during a spring bloom in Villefranche-sur-Mer Bay, Mediterranean Sea. J. exp. mar. Biol. Ecol. 129: 17-32

Costantopoulous, G, Bloch, K. (1967). Effect of light intensity on the lipid composition of Euglena gracilis. J. biol. Chem. 242: $3538-3542$

Cullen, J. J., Neal, P. J., Lesser, M. P. (1992). Biological weighting function for the inhibition of photosynthesis by ultraviolet radiation. Science 258: 646-650

DeMort, C. L., Lowry, R., Tinsley, I., Phinney, H. K. (1972). The biochemical analysis of some estuarine phytoplankton species. 1 Fatty acid composition. J. Phycol. 8: 211-216

Dohler, G. (1984). Effect of UV-B radiation on the marine diatoms Lauderia annulata and Thalassiosira rotula grown in different salinities. Mar. Biol. 83: 247-253

Dohler, G. (1985). Effect of UV-B radiation on the nitrogen metabolism of several marine diatoms. J. Plant Physiol. 118: $391-400$

Dohler, G. (1988). Impact of UV-B radiation on nitrogen metabolism of marine phytoplankton. In: Öztürk, M. A. (ed.) International symposium on plants as pollutants of developed and developing countries. Ege University, Izmir, p. 57-87

Dohler, G. (1989a). Influence of UV-B (290-320 nm) radiation on photosynthetic ${ }^{14} \mathrm{CO}_{2}$ fixation of Thalassiosira rotula (Meunier). Biochem. Physiol. Pflanz. 185: 221-226

Dohler, G. (1989b). Impact of UV-B radiation on ${ }^{15} \mathrm{~N}$ incorporation into free amino acids of Ditylum brightwellit. Oceanis 15: 571-586

Dohler, G. (1990). Effect of UV-B $(290-320)$ radiation on 
uptake of ${ }^{15} \mathrm{~N}$-nitrate by marine diatoms. In: Ullrich, W. R. et al. (eds.) Inorganic nitrogen in plants and microorganisms. Uptake and metabolism. Springer-Verlag, Berlin, p. $349-354$

Dohler, G. (1992). Impact of UV-B radiation on uptake of ${ }^{15} \mathrm{~N}$ ammonia and ${ }^{15} \mathrm{~N}$-nitrate by phytoplankton of the Wadden Sea. Mar. Biol. 112: 485-489

Dohler, G., Hagmeier, E., Grigoleit, E., Krause, K. D. (1991). Impact of solar UV radiation on uptake of ${ }^{15} \mathrm{~N}$-ammonia and ${ }^{15} \mathrm{~N}$-nitrate by marine diatoms and natural phytoplankton. Biochem. Physiol. Pflanz. 187: 293-303

Dohler, G., Worrest, R.C., Biermann, I., Zink, J. (1987). Photosynthetic ${ }^{14} \mathrm{CO}_{2}$ fixation and ${ }^{15} \mathrm{~N}$-ammonia assimilation during UV-B radiation of Lithodesmium variable. Physiologia Pl. 70: 511-515

Falkowski, P. G. (1980). Light shade adaptation in microalgae. In: Falkowski, P. G. (ed.) Primary productivity in the sea Plenum Press, New York, p. 99-119

Forde, J., Steer, M. W. (1976). The use of quantitative electron microscopy in the study of lipid composition of membranes. J. exp. Bot. 27: 1137-1141

Fuller, G., Nes, W. D. (1987). Plant lipids and their interactions. In: Fuller, G., Nes, W. D. (eds.) Ecology and metabolism of plant lipids. ACS Symp. Ser. 325: 2-8

Goldberg, I., Ohad, I. (1970). Biogenesis of chloroplast membranes IV. Lipid and pigment changes during synthesis of chloroplast membranes in a mutant of Chlamydomonas reinhardi $y-1$. J. Cell Biol. 44:563-571

Guillard, R. R. L., Ryther, J. H. (1962). Studies on marine planktonic diatoms. I. Cyclotella nana (Husted) and Detonula conferveracea (Cleve.) Gran. Can. J. Microbiol. 8: $229-239$

Hader, D. P., Watanabe, M., Furuya, M. (1986). Inhibition of motility in the cyanobacterium Phormidium uncinatium by solar and monochromatic UV irradiation. Plant Cell. Physiol. 27 : $887-894$

Hama, J., Handa, N. (1992). Diel variation of waterextractable carbohydrate composition of natural phytoplankton populations in Kinu-ura Bay. J. exp. mar. Biol. Ecol. 162: 159-176

Hama, T. (1988). ${ }^{13} \mathrm{C}$ GC-MS analysis of photosynthetic products of the phytoplankton population in the regional upwelling area around the Izu Islands, Japan. Deep Sea Res. 35: 91-110

Hama, T (1991). Production and turnover rates of fatty acids in marine particulate matter through phytoplankton photosynthesis. Mar. Chem. 33: 213-227

Hama, T., Hama, J., Handa, N. (1993). ${ }^{13} \mathrm{C}$ tracer methodology in microbial ecology with special reference to primary production processes in aquatic environments. In: Jones, J. G. (ed.) Advances in microbial ecology, Vol. 13. Plenum Press, New York, p. 39-83

Hama, T., Handa, N. (1987). Pattern of organic matter production by natural phytoplankton population in a eutrophic lake. 1. Intracellular products. Arch. Hydrobiol. 109: $107-120$

Hama, T., Handa, N., Hama, J. (1987). Determination of amino acid production rate of a marine phytoplankton population with ${ }^{13} \mathrm{C}$ and gas chromatography-mass spectrometry. Limnol. Oceanogr. 32: 1144-1153

Hama, T., Miyazaki, T., Ogawa, Y., Iwakuma, T., Takahashi, M., Otsuki, A., Ichimura, S. (1983). Measurement of photosynthetic production of a marine phytoplankton population using a stable isotope. Mar. Biol. 73: 31-36

Harris, R. V., Harris, P., James, A. T (1965). The fatty acid metabolism of Chlorella vulgaris. Biochim. Biophys. Acta 106: $465-473$
Harwood, J. L. (1988). Fatty acid metabolism. A. Rev. Plant Physiol. 39: 101-138

Harwood, J. L., Russell, N. J. (eds.) (1984). Lipids in plants and microbes. George Allen and Unwin, London

Helbling, W.E., Villafane, V., Ferrario, M., Holm-Hansen, O (1992). Impact of natural ultraviolet radiation on rates of photosynthesis and on specific marine species. Mar Ecol. Prog. Ser. 80: 89-100

Hellyer, A., Bambridge, H. E., Slabas, A. R. (1986). Plant acetyl Co-A carboxylase. Biochem. Soc. Trans. 14 $565-568$

Herndl, G. J., Muller-Niklas, G., Frick, J. (1993). Major role of ultraviolet-B in controlling bacterioplankton growth in the surface layer of the ocean. Nature 361:717-719

Holm-Hansen, O., Helbling, E. W., Lubin, D. (1993). Ultraviolet radiation in Antarctica: Inhibition of primary production. Photochem. Photobiol. 58: 567-570

Huang, K. P., Stumpf, P. K. (1971). Fatty acid synthesis by a soluble fatty acid synthetase from Solanum tuberosum. Arch. Biochem. Biophys. 143: 412-427

Huntley, M. E., Cimiiello, P., Lopez, M. D. G. (1987). Importance of food quality in determining development and survival of Calanus pacificus (Copepoda: Calanoida). Mar. Biol. 95: 103-113

Iwanzik, W., Tevini, M. Voss, M., Weiss, W., Graber, P., Renger, G. (1983). Action of UV-B radiation on photosynthetic primary reactions in spinach chloroplasts. Physiol. Plant. 58: 401-407

Jeffrey, S. W., Humphrey, G. F. (1976). New spectrophotometric equations for determining chlorophylls $a, b, c 1$ and $c 2$ in higher plants, algae and natural phytoplankton. Biochem. Biophys. Pflanz. 167. 191-194

Karentz, D., Lutze, L. H. (1990). Evaluation of biologically harmful ultraviolet radiation in Antarctica with a biological dosimeter designed for aquatic environments. Limnol. Oceanogr. 35: 549-561

Kates, M. (1972). Isolation, analysis and identification of lipids. In: Work, T S., Work, E. (eds.) Techniques in lipidology. Elsevier, Amsterdam, p. 268-618

Kates, M., Volcani, B. E. (1966). Lipid components of diatoms. Biochim. Biophys Acta 116: 264-278

Kouchi, H. (1982). Direct analysis of ${ }^{13} \mathrm{C}$ abundance in plant carbohydrates by gas chromatography-mass spectrometry. J. Chromatogr. 241: 305-323

Newton, J. W., Tyler, D. D., Slodki, M. E. (1979). Effect of ultraviolet-B $(280-320 \mathrm{~nm})$ radiation on blue green algae (Cyanobacteria), possible biological indicators of stratospheric ozone depletion. Appl. environ. Microbiol. 37: $1134-1141$

Nichols, B. W. (1965). Light induced changes in the lipids of Chlorella vulgaris. Biochim. Biophys. Acta 106: 274-279

Nichols, B. W., James, A. T (1968). Acyl lipids and fatty acids of photosynthetic tissue. In: Reinhold, L., Liwschitz, Y. (eds.) Progress in phytochemistry, Vol. 1. Interscience, New York, p. 1-48

Opute, F. I. (1974). Studies on fat accumulation in Nitzschia palea Kutz. Ann. Bot. 38: 889-902

Pohl, P. (1974). Control of unsaturated fatty acid biosynthesis in unicellular algae by the nitrogen content of the nutrient medium and by the wavelength of light. J. Am. Oil Chem. Soc. 51: 521A

Pohl, P., Wagner, H. (1972). Control of fatty acid and lipid biosynthesis in Euglena gracilis by ammonia, light and DCMU. Z. Naturforsch. 27: 53-61

Prezelin, B. B. (1981). Light reactions in photosynthesis. In: Platt, Y (ed.) Physiological bases of phytoplankton ecology. Can. Bull. Fish. Aquat. Sci. 210: 44-54 
Renger, G., Voelker, M. H. J., Eckert, H. J., Fromme, R., HohmVeit, S., Graeber, P. (1989). On the mechanism photosystem II deterioration by UV-B radiation. Photochem. Photobiol. 49: 97-106

Rigano, C.. Di Martino-Rigano, V., Vona, V.. Fuggi, A. (1980). Nitrate reductase and glutamine synthetase activities, nitrate and ammonia assimilation in the unicellular alga Cyanidum caldarum. Arch. Microbiol. 129: 110-114

Roessler, P. G. (1990). Environmental control of glycerolipid metabolism in microalgae: commercial implications and future research directions. J. Phycol. 26: 393-399

Rosenberg, A., Gouaux, J. (1967). Qualitative and compositional changes in monogalactosyl and digalactosyl diglycerides during light-induced formation of chloroplasts in Euglena gracilis. J. Lipid Res. 8: 80-83

Sargent, J. R., Whittle, K. J. (1981). Lipids and hydrocarbons in the marine food web. In: Longhurst, A. (ed.) Analysis of marine ecosystems. Academic Press, London, p. 491-533

Siron, R., Giusit, G., Berland, B. (1989). Changes in the fatty acid composition of Phaeodactylum tricornutum and Dunaliella tertiolecta during growth and under phosphorous deficiency. Mar. Ecol. Prog. Ser. 55: 95-100

Smith, R. C., Baker, K. S. (1989). Stratospheric ozone, middle ultraviolet radiation and phytoplankton productivity. Oceanogr. Mag. 2: 4

Smith, R. C., Prezelin, B. B., Baker, K. S., Bidigare, R. R., Boucher, N. P., Coley, T., Karentz, D., Macintyre, S., Matlick, H. A., Menzies, D., Ondrusek, M., Wan, Z., Waters, K. J. (1992). Ozone depletion: ultraviolet radiation

This article was submitted to the editor and phytoplankton biology in Antarctic waters. Science 255: $952-959$

Tevini, M. (ed.) (1993). UV-B radiation and ozone depletion. effects on humans, animals, plants, microorganisms and materials. Lewis Publishers, Tokyo

Thompson, P. J., Harrison, P. J., Whyte, J. N. C. (1990). Influence of irradiance on the fatty acid composition of phytoplankton. J. Phycol 26: 278-288

UNEP (1991). International committee on effects of ozone depletion. UNEP report on the environmental effects of ozone depletion. United Nations Environmental Programme, New York

Volkman, J. K., Jeffrey, S. W., Nichols, P. D., Rogers, G. I., Garland, C. D. (1989). Fatty acid and lipid composition of 10 species of microalgae used in mariculture. J. exp. mar. Biol. Ecol. 128: 219-240

Vosjan, J. H., Dohler, G., Nieuwland, G. (1990). Effect of UV-B irradiance on the ATP content of microorganisms of the Weddell Sea (Antarctica). Neth. J. Sea Res. 25: 391-393

Watanabe, T., Kitajima, C., Fujita, S. (1983). Nutritional values of live organisms used in Japan for the mass propagation of fish: a review. Aquaculture 34: 115-143

Worrest, R. C. (1982). Review of literature concerning the impact of LV-B radiation upon marine organisms. In: Calkins, J. (ed.) The role of solar ultraviolet radiation in marine ecosystems. Plenum Press, New York, p. 429-457

Worrest, R., Hader, D. P. (1989). Effect of stratospheric ozone depletion on marine organisms. Environ. Conserv. 16: 261-263

Manuscript first received: November 30, 1993

Revised version accepted: July 18, 1994 